\title{
DIAMINO-DIPHENYL SULPHOXIDE IN THE TREATMENT OF LEPROSY: A DEFINITIVE REPORT ON EXPANDED TRIALS
}

\author{
By S. G. Browne, M.D., F.R.C.S., M.R.C.P., D.T.M., \\ and T. F. DaveY, C.B.E., M.D., M.Sc. \\ Leprosy Service Research Unit, Uzuakoli, \\ Eastern Nigeria
}

Further experience gained in the treatment of leprosy with Diamino-diphenyl sulphoxide (DDSO) in the Research Unit at Uzuakoli and in several neighbouring leprosy settlements, subsequent to the progress report by Davey et al. (1957), has substantiated certain of the earlier findings and has amplified the tentative conclusions reached concerning the toxic qualities of the product.

Cognisant of the warning contained in the above report that certain observed abnormalities might prove serious at higher dose levels, and having been informed that the drug was potentially toxic, the Tokyo Congress (1958) passed a Technical Resolution to the effect that further studies of the drug, especially its toxicity and its use in the later stages of treatment, should be undertaken.

This definitive report on expanded trials with DDSO embodies the results of further study and attempts to answer outstanding questions regarding toxicity and therapeutic value.

It is recalled that DDSO was recognized as a bactericidal agent principally through the invest igations of Fourneau et al. (1937) Buttle et al. (1938), and that Buu-Hoi et al. (1955) first used the drug in the treatment of leprosy. In addition to Davey et al. (1957) in Eastern Nigeria, Laviron et al. (1957) and others have employed the drug elsewhere.

On the analogy of the good results obtained with Dapsone in the treatment of dermatitis herpetiformis, DDSO has been given for this condition (Alexander, 1958).

\section{Choice of patients}

The patients who took part in this expanded trial represented a typical cross-section of leprosy as it occurs among patients seeking admission into settlements in Southern Nigeria. They were unselected as regards age, sex and duration of the disease. Most of them had received no previous treatment.

The following settlements co-operated with Uzuakoli: Oji River, Isoba, Itu, Uburu, Abakaliki and Ossiomo. 
Clinical forms of leprosy

$\begin{array}{lr}\text { Lepromatous } & 64 \\ \text { Borderline } & 6 \\ \text { Tuberculoid } & 44 \\ \text { Indeterminate } & 8\end{array}$

Some of the patients originally classified as "lepromatous" or "tuberculoid" subsequently developed borderline features.

\section{Dosage of the drug}

For the purposes of the pilot trial, it was inferred that since the molecular structure of DDSO resembled that of Dapsone, dosage scales should be similar to those employed with Dapsone. The scales then adopted were continued throughout the present trial.

Adult patients received the drug in the following doses during a cautious build-up (which has been held to minimize the risk of toxic complications, especially dermatitis): 70 patients received $100 \mathrm{mgm}$. twice weekly for 3 weeks; $200 \mathrm{mgm}$. twice weekly for 3 weeks; and $300 \mathrm{mgm}$. twice weekly thereafter; 37 patients received $100 \mathrm{mgm}$. daily for six days a week; 7 children received $50 \mathrm{mgm}$. daily, and 8 adolescents received $200 \mathrm{mgm}$. twice weekly, as definitive doses.

The average weight of the adults was $124 \mathrm{lbs}$. $(56.4 \mathrm{~kg}$.), and the average age was 33 years.

\section{Controls}

For the first 24 months of the trial at Uzuakoli, patients under treatment with DDSO were paired with patients undergoing standard Dapsone treatment. Once the absolute efficacy of the drug had been established, precise comparative studies with paired patients were discontinued.

It was at first considered that the therapeutic action of DDSO was somewhat different from that of Dapsone in the following respects: with similar doses the clinical and bacteriological improvement was greater; smaller doses were effective; the toxic signs followed a different pattern, anaemia being less marked and liver damage occurring relatively late; DDSO was thought not to precipitate neuritis and lepra reaction as frequently as did Dapsone.

Further experience has not substantiated the earlier impressions, except as regards toxicity: specifically, a pattern of kidney damage became apparent to which detailed reference will later be made. 


\section{Duration of treatment}

Treatment was continued with DDSO for an average of 36 months for bacteriologically positive patients and for 30 months for the bacteriologically negative.

\section{Progress under therapy: Clinical}

As with other treatments for leprosy, clinical progress has not been uninterrupted in all cases. Several patients admitted to treatment in an active or progressive phase of the disease showed some exacerbation before steady improvement became established.

The results of treatment in this expanded trial do not differ materially from those obtained in patients receiving Dapsone in standard doses. Taking all clinical criteria into consideration, the following assessment of progress was made in those who continued treatment with the drug till the end of the trial.

$$
\begin{array}{llll}
\text { Excellent } & \ldots & \ldots & 23 \\
\text { Good } \ldots & \ldots & \ldots & 65 \\
\text { Fair or Slight } & \ldots & \ldots & 17
\end{array}
$$

\begin{tabular}{|c|c|c|c|}
\hline Haematuria & .. & $\ldots$ & \\
\hline Dermatitis & & 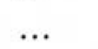 & $\ldots$ \\
\hline Severe lepra & action & $\ldots$ & $\ldots$ \\
\hline Psychosis (in & uding & ne pat & ent \\
\hline with hepa & & $\ldots$ & $\ldots$ \\
\hline Hepatitis & $\ldots$ & $\ldots$ & $\ldots$ \\
\hline Death (from & ellow & Fever) & .. \\
\hline
\end{tabular}

In the remaining 17 patients, treatment was discontinued for the following reasons:

Of the 70 Uzuakoli patients, 27 who had received no drug but DDSO were discharged symptom-free, and 16 out of 33 bacteriologically negative patients were considered to require further treatment after having received the drug for 30 months. Subsequent progress has been without incident in these patients, and similar to that expected if Dapsone had been the drug originally employed.

\section{Bacteriological}

Most bacteriologically positive patients had smears examined at eight sites at monthly intervals. The collated results are expressed in the accompanying figure.

The rate of morphological degeneration of the M.leprae in the routine smears resembled the pattern habitually observed in patients under Dapsone therapy. 


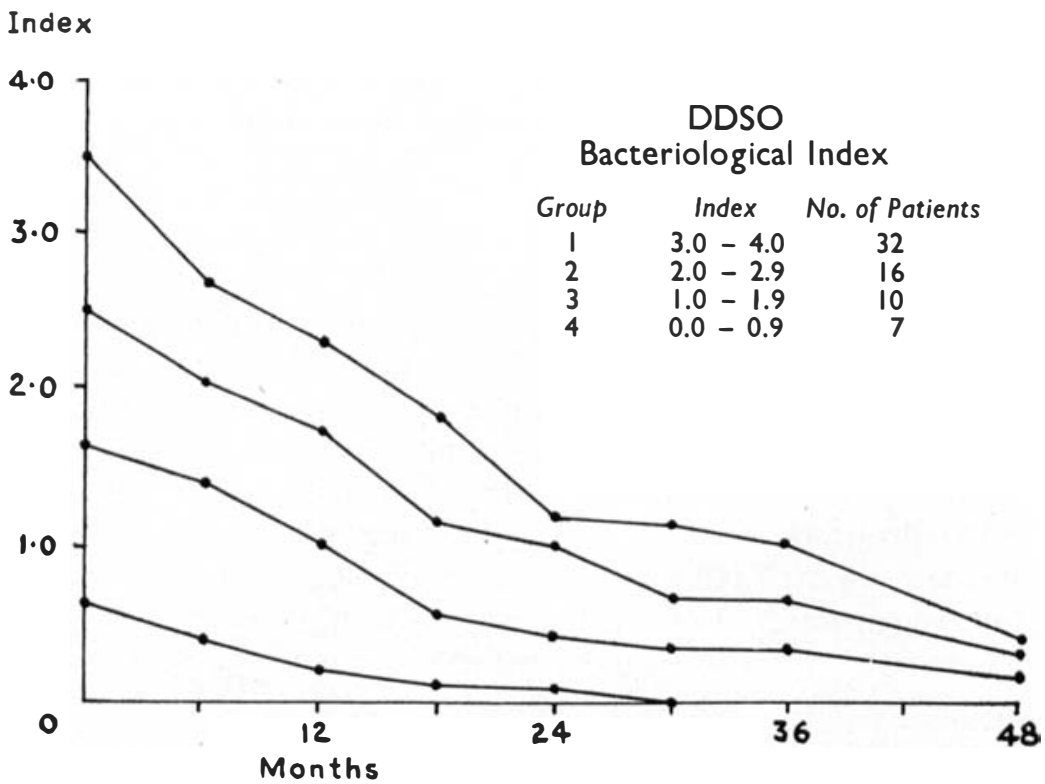

After making progress similar to that of other patients with disease of comparable severity, 4 patients suddenly showed an increase in the Bacteriological Index, with reappearance of M.leprae of normal morphology in the routine smears. Normal bacilli were first seen in the nasal mucosa in one patient, in the cutaneous lesions in another, and in both skin and ear lobes in the remaining two patients. The raised Index persisted for a variable period before returning to the pre-existing level and then resuming its downward trend; normal bacilli usually disappeared as the Index fell. The sustained nature of the elevation would suggest that the findings were not fortuitously dependent on the hazards of smearing but may be explicable on other grounds.

The increase occurred in all four patients in the rainy season; all had lepra reaction with erythema nodosum at the time; one of them was suffering from severe anaemia which had necessitated reduction in the dose of drug.

\begin{tabular}{|c|c|c|c|c|c|c|c|c|}
\hline $\begin{array}{c}\text { Serial } \\
\text { No. }\end{array}$ & Age & $\begin{array}{c}\text { B.I. on } \\
\text { admission }\end{array}$ & \multicolumn{2}{|c|}{$\begin{array}{l}\text { Length of } \\
\text { treatment } \\
\text { before B.I. } \\
\quad \text { rose }\end{array}$} & $\begin{array}{l}\text { B.I. in } \\
\text { the month } \\
\text { before } \\
\text { the rise }\end{array}$ & $\begin{array}{c}\text { Raised } \\
\text { B.I. }\end{array}$ & \multicolumn{2}{|c|}{$\begin{array}{c}\text { Duration of } \\
\text { raised BI. } \\
\text { before return } \\
\text { to pre-existing } \\
\text { level }\end{array}$} \\
\hline 9750 & 6 & 2.8 & \multicolumn{2}{|c|}{34 months } & 2.6 & 3.4 & \multicolumn{2}{|c|}{16 months } \\
\hline 9749 & 6 & 1.8 & 11 & , & 1.5 & 2.0 & 11 & , \\
\hline 9769 & 12 & 3.0 & 27 & , & 0.9 & 1.7 & 27 & , \\
\hline 2474 & 40 & 3.4 & 26 & , & 0.8 & 1.6 & 25 & , \\
\hline
\end{tabular}




\section{Relapses}

Of the total of 47 patients who have been discharged from Uzuakoli with the disease clinically arrested (27 having received DDSO only), 35 have attended subsequently for examination, most of them more than once. Of these, 3 patients have relapsed, 2, 10 and 12 months respectively af ter discharge; there are almost certainly no relapses apart from these three. In two of the three, M.leprae were found in the smears: one of them had been bacteriologically negative for 14 months before discharge, and the other had never been positive. Bacilli were present in the ear-lobes of both patients, and also in the skin lesion in one, and in the nasal mucosa in the other.

All three relapses were in patients whose lesions have subsequently shown Borderline features, indicating immunological instability. The duration of treatment with DDSO (none having received any other treatment) had been 25,26 and 38 months. In retrospect, it is evident that treatment of these patients should have continued for longer.

\section{Toxicity}

Since DDSO possesses no obvious advantage over Dapsone in the treatment of leprosy, and since it is, moreover, at least twice as expensive to manufacture, its sphere of use will be determined by its toxicity and the incidence of undesirable side-effects.

\section{Anaemia}

In addition to the signs of slight initial reduction in haemoglobin levels already reported, two patients under therapy experienced more severe anaemia.

\section{Dermatitis}

Several types of cutaneous reaction to DDSO were noted: in four patients they were sufficiently severe to warrant suppression of the drug.

1. A papular irritating dermatitis in two patients. In one, the dermatitis recurred with every administration of the drug; a slow desensitization with aqueous Solapsone was successful, and treatment was eventually resumed.

2. A diffuse melanosis, facial in one patient, and generalized on the trunk in two others;

3. A discrete $\bar{h}$ hypermelanotic macular rash, in one patient, similar to the cases reported by Browne $(1959,1960)$ with Dapsone and Solapsone; 
4. Marked hypermelanosis of lepromatous infiltration was seen on the face, particularly the forehead and cheeks, in two patients.

Three patients showed parallergic sensitivity to DDSO and to Dapsone; one of them was also sensitive to Ditophal ("Etisul"), and another to both Ditophal and the barbiturates. On the other hand, one patient who was sensitive to Dapsone, received DDSO for 20 months before developing dermatitis.

\section{Lepra reaction}

Fourteen of the 64 lepromatous patients under treatment developed lepra reaction with erythema nodosum, of varying severity.

\section{Iritis}

Two patients had iritis.

\section{Neuritis}

Twenty-four patients developed neuritis of one or more main superficial nerve trunks during the trial.

\section{Psychosis}

Three patients, with no obvious history of mental instability, developed psychotic symptoms. In two, although clinical progress had been satisfactory in other respects, treatment with the drug had to be abandoned.

\section{Hepatitis}

Two patients developed clinical signs of liver damage, after two years of treatment.

Schlesinger's test (for urobilin) was performed every month on all Uzuakoli patients. From the 16th to the 25th months inclusive, this delicate test was positive on 47 occasions, and in 6 patients definitely abnormal findings were reported on 10 occasions between the 20th and 26th months: in 2 of these the liver was slightly enlarged and tender.

One patient died after a brief illness characterized by pyrexia, jaundice and coma, with massive albuminuria. The liver showed the typical histological picture of Yellow Fever.

\section{Kidney damage}

The toxic action of DDSO on the kidneys, already suspected, has been confirmed.

In the majority of the 70 Uzuakoli patients concerning whom detailed laboratory data were available, albuminuria was discovered 
on at least one occasion during the course of treatment. In the last 12 months of the trial a "clean" specimen of urine obtained from all patients having a trace of albumin, failed to show albumin in approximately one-half of the specimens. In about one-half of the remainder, the albumin may have arisen in tissues other than glomeruli or tubules, for, in addition to epithelial cells and leucocytes, these specimens contained one of the following: gonococci, spermatozoa, oxalate or triple phosphate crystals, Trichomonas vaginalis. No schistosome ova were found, and no crystals other than those mentioned.

A total of 36 patients had albuminuria, probably of renal origin, at some period during the trial. In 28 , a "faint trace" was recorded at least once, but in seven of these erythrocytes were present in the deposit after centrifugation, and in two, casts were found. All seven patients whose urine contained "I plus" of albumin at least once, passed erythrocytes in the specimen that contained albumin, and two had casts in addition. In the single specimen in which the amount of albumin was returned as " 2 plus", erythrocytes and casts were also present.

The erythrocytes were generally scanty, under 3 per field (of the $\frac{1}{6}$-inch objective) of the deposit after centrifugation; they occurred mainly from the 11 th to the 13 th months of treatment, and from the 22 nd to the $24 \mathrm{th}$, but few months were entirely exempt.

In the course of the trial DDSO was discontinued in eight patients because of persistent microscopic haematuria. After improvement in the urinary condition, another anti-leprosy treatment was instituted.

When the nephrotoxic action of the drug was beyond doubt, the trial was concluded. Thereafter slight albuminuria persisted in 12 patients intermittently for some months ( 1 to 19$)$; in two patients, microscopic haematuria persisted for 2 and 5 months respectively, and casts were found in one of the latter up till 2 months.

The presence of erythrocytes in the urine was not related to the reaction of the urine; nor to pyuria-infection with resistant organisms can thus be excluded. It could not be correlated with the dose/body-weight ratio, or with the frequency of administration of the drug.

Dysuria and strangury were absent, except in one patient, who complained of these symptoms after the drug had been suppressed.

The blood urea was estimated in 25 patients, in 16 of them twice. In all cases, it was within normal limits. In nine patients, the second examination gave slightly lower readings than the first performed six months previously.

It is inferred from these findings that the unchanged drug or certain of its metabolites have a nephrotoxic action, slight or moderately severe, and usually transient, in a regrettably high pro- 
portion of patients receiving standard doses of DDSO for the prolonged periods necessary for the adequate treatment of leprosy.

Earlier reports concerning kidney damage with the drug have been made. Kimmig (1948) declared that its potential toxicity for the kidney rendered its use inadvisable in human disease; but Buttle et al. (1938), and Laviron et al. (1957) did not consider it more toxic than Dapsone.

Alexander (1958) using DDSO for dermatitis herpetiformis, in relatively high doses up to $200 \mathrm{mgm}$. daily, mainly in elderly patients, reported a high incidence of urinary complications after a short period of treatment. Haematuria was noted in 3 patients out of 11 , frequency of micturition in 7, dysuria in 4. The urine contained Esch. coli in 2 patients and Staph. aureus in one.

It is known that DDSO is partly converted into Dapsone and excreted as such (Levi \& Snow, 1960), but it is unlikely that this moiety could account for the toxic effects noted in such a high proportion of patients, since it is distinctly uncommon for Dapsone in standard doses to cause haematuria in leprosy patients on prolonged treatment. Combes and Reisch (1957) reported 3 patients who developed “cystitis" under Dapsone therapy, and Verma (1958) reported one. Van Ketel (1960) recorded three urinary tract infections among 13 patients treated with Dapsone (Cf. Alexander's cases, referred to above, of the same disease treated with DDSO); but Kroichik and Tumasheva (1960) specifically mention the absence of urinary tract infections in 54 patients treated with Dapsone for psoriasis and other dermatoses.

\section{Conclusions}

1. Diamino-diphenyl sulphoxide has a definite anti-leprosy action in doses of the order of $300 \mathrm{mgm}$. twice weekly or $100 \mathrm{mgm}$. daily by the mouth.

2. Clinical improvement is obtained in all varieties of leprosy.

3. Reduction in the Bacteriological Index and disappearance of morphologically normal M.leprae generally follow a consistent pattern.

4. The clinical and bacteriological amelioration is similar in all respects to that with Dapsone.

5. The incidence of such side-effects as anaemia, psychosis, lepra reaction and erythema nodosum and hepatitis appears to be similar to that in comparable groups of patients undergoing Dapsone therapy.

6. The incidence of dermatitis is higher with DDSO than with Dapsone.

7. In a high proportion of patients who receive standard doses of the drug over prolonged periods, DDSO has a direct nephrotoxic 
action shown by the occurrence of albuminuria, and haematuria, and the passage of casts.

8. Notwithstanding its therapeutic efficacy in the treatment of all types of leprosy, the nephrotoxic action of the drug renders its further use inadvisable.

\section{Acknowledgments}

Our thanks are due to the Medical Officers who, in leprosy settlements in the Eastern Region of Nigeria, co-operated in this trial: Drs. A. S. Garrett, K. Ellis and W. F. Ross (Oji River); M. G. Corcos, and A. Paklikowski (Isoba); M. Phillips (Itu); A. McDonald (Uburu); M. Chambers, E. Fern and D. McLoughlin (Abakaliki); and B. Nicholson at Ossiomo in the Western Region.

Special thanks are expressed to Dr. L. M. Hogerzeil, Area Superintendent of Owerri Province, Uzuakoli Settlement, for his ready help during the trial. The Yellow Fever services of the Yaba Federal Laboratory were responsible for the histological diagnosis of Yellow Fever in the case recorded.

We acknowledge with gratitude the generous supply of Diaminodiphenyl sulphoxide placed at our disposal by Messrs. Imperial Chemical Industries (Pharmaceuticals) Ltd., and particularly the help of Dr. J. Michael Mungavin.

We are grateful to Dr. S. E. Onwu, M.V.O., O.B.E., Chief Medical Officer, Director of Medical Services and Permanent Secretary, Ministry of Health, Eastern Region, Nigeria, for permission to publish.

\section{References}

Alexander, J. O’D., Lancet (1958) 2, 1181.

Browne, S. G., Trans. R. Soc. Trop. Med. Hyg. (1959) 53, 495.

Browne, S. G., Leprosy Rev. (1960) 31, 54.

Buttle, G. A. H., Dewing, T., Foster, G. E., Gray, W. H., Smith, S., and Stephenson, D., Biochem. J. (1938) 30, 1101.

Buu-Hoi, Ng. Ph., Nguyen-Ba Khuyen and Nguyen-Dat-Xuong, Bull. Acad. Med., Paris (1955) 139, 275.

Combes, F. C., and ReisCH, M., Brit. J. Derm. (1957) 69, 25.

Davey, T. F., Kissaun, A. M., and Moneta, G., Leprosy Rev. (1957) 28, 51.

Fourneau, E., Trefouel, J., and Mme. J., Netti, F., and Bovet, D., Bull. Acad. Med., Paris (1937) 118, 210.

Kimmig, J., Arch. Dermat. u. Syph. (1948) 186, 156.

Kroichik, A. A., and Tumasheva, N. I., Vesinik Dermatol. $i$ Venerol. (1960) 34, 70 .

Laviron, P., Lauret, L., Kerbastard, P., and Jardin, Cl., Bull. Acad. Med., Paris (1957) 141, 195.

Levi, A. A., and Snow, G. A., Brit. J. Pharm. Chemother. (1960) 15, 160.

Tokyo Conference. Transactions of the VIIth International Congress of Leprology (1958). Tofu Kyokai (Japanese Leprosy Foundation) Tokyo, Japan.

Van KeTEL, W. G., Nederl. Tijdschr. Geneesk. (1960) 41, 1986.

Verma, B. S., Indian J. Derm. (1958) 4, 54. 